\title{
REANÁLISE DE \\ VARIÁVEIS SEMÂNTICAS \\ NO CONDICIONAMENTO DO \\ OBJETO NULO E DO PRONOME \\ PLENO NA FALA DE \\ FLORIANÓPOLIS
}

\author{
REANÁLISIS DE LAS VARIABLES SEMÁNTICAS EN EL CONDICIONAMIENTO DEL OBJETO \\ NULO Y DEL PRONOMBRE EXPLÍCITO EN EN EL HABLA DE FLORIANÓPOLIS
}

REANALYSIS OF SEMANTIC VARIABLES IN THE CONDITIONING OF THE NULL OBJECT AND THE TONIC PRONOUN IN THE SPEECH OF FLORIANOPOLIS

Izete Lehmkuhl Coelho*

Universidade Federal de Santa Catarina

Gabriel de Ávila Othero**

Universidade Federal do Rio Grande do Sul

Cecília Augusta Vieira-Pinto***

Universidade Federal de Santa Catarina

RESUMO: Neste artigo, analisamos as ocorrências de objeto direto anafórico de $3^{\text {a }}$ pessoa, investigando duas estratégias produtivas em português brasileiro: o pronome pleno (ele/ela) e o objeto nulo $(\mathrm{ON})$. Visto que essas duas estratégias não estão em variação livre, nosso objetivo foi verificar qual traço semântico do antecedente estaria condicionando o uso das duas variantes. Baseando-nos em literatura recente (CREUS; MENUZZI, 2004; PIVETTA, 2015; AYRES, 2016; OTHERO et al. 2016, OTHERO; SCHWANKE, 2017), decidimos reanalisar os dados de Vieira-Pinto (2015) e Vieira-Pinto e Coelho (2016), em sua pesquisa com entrevistas sociolinguísticas de Florianópolis, verificando três variáveis semânticas: animacidade, especificidade e gênero semântico do

\footnotetext{
* Doutora em Linguística pela Universidade Federal de Santa Catarina - UfSC. Professora Associada da Universidade Federalde Santa Catarina - UFSC. Bolsista de ProdutividadedoCNPq. E-mail: izete@cce.ufsc.br.

** Doutor em Linguística pela Pontifícia Universidade Católica do Rio Grande do Sul - PUCRS. Professor Adjunto no Instituto de Letras da Universidade Federaldo Rio GrandedoSul - UFRGS. E-mail: gab.othero@gmail.com. 
antecedente. Confirmando a hipótese de Creus e Menuzzi (2004), concluímos que o gênero semântico é o traço mais importante da retomada anafórica de objeto, no seguinte sentido: antecedentes com traço [+gênero semântico] favorecem o pronome pleno, enquanto antecedentes com [-gênero semântico] favorecem o objeto nulo.

PALAVRAS-CHAVE: Objeto direto anafórico. VARSUL. Gênero semântico. Gramática do português brasileiro.

RESUMEN: En este artículo analizamos las ocurrencias del objeto directo anafórico de $3^{\text {a }}$ persona e investigamos dos estrategias productivas en el portugués brasileño (PB): el pronombre explícito en esa variedad (ele/ela) y el objeto nulo (ON). Dado que esas dos estrategias no están en variación libre, nuestro objetivo fue verificar cuál es el rasgo semántico del antecedente que estaría condicionando el uso de las dos variantes. Con base en la literatura reciente (cf. CREUS; MENUZZI, 2004; PIVETTA, 2015; AYRES, 2016; OTHERO et al. 2016: OTHERO; SCHWANKE, 2017), decidimos reanalizar los datos de Vieira-Pinto (2015) y Vieira-Pinto y Coelho (2016) en su estudio con entrevistas sociolingüísticas de Florianópolis (sur de Brasil), constatando tres variables semánticas: animicidad, especificidad y género semántico del antecedente. A través de la reafirmación de la hipótesis de Creus y Menuzzi (2004), concluimos que el género semántico es la variable más significativa de la recuperación anafórica del objeto directo en $\mathrm{PB}$, en el siguiente sentido: antecedentes con rasgo [+género semántico] favorecen el pronombre explícito, mientras que antecedentes con [-género semántico] favorecen el objeto nulo.

PALABRAS CLAVE: Objeto directo anafórico. VARSUL. Género semántico. Gramática del portugués brasileño.

ABSTRACT: In this article, we analyzed the third person anaphoric direct object, investigating two very productive strategies in Brazilian Portuguese: the tonic pronoun (elelela, 'helshe') and an empty category (a null object). Since these two strategies are not in free variation, our main goal was to verify which semantic feature of the antecedent might be serving as internal conditioning for the use of tonic pronouns or the empty category. Based on recent literature on the subject (CREUS; MENUZZI, 2004; PIVETTA, 2015; AYRES, 2016; OTHERO et al. 2016; OTHERO; SCHWANKE, 2017), we decided to re-examine the data presented in VieiraPinto (2015), and Vieira-Pinto and Coelho (2016) using sociolinguistic interviews from the Florianópolis. We investigated three variables related to the NP antecedent: animacy, specificity and semantic gender. Confirming the hypothesis originally proposed by Creus e Menuzzi (2004), we conclude that the semantic gender of the antecedent is the main feature for the phenomenon of the anaphoric direct object, as follows: antecedents with identified semantic gender favor pronominal anaphora, whereas antecedents without identified semantic gender favor the null object.

KEYWORDS: Anaphoric direct object. VARSUL project. Semantic gender. Brazilian Portuguese grammar.

\section{INTRODUÇÃO}

A proposta deste artigo surgiu de uma parceria entre os autores no sentido de verificar a força de uma variável interna, o gênero semântico do sintagma nominal (SN) antecedente, no condicionamento da retomada anafórica de objeto direto, a partir de dados de fala, investigados por Vieira-Pinto (2015) e Vieira-Pinto e Coelho (2016). Nesses trabalhos, as autoras analisaram as estratégias de retomada anafórica do objeto direto de $3^{\text {a }}$ pessoa em entrevistas sociolinguísticas de dois períodos cronológicos (década de 1990 e década de 2010) de Florianópolis, conforme veremos com detalhes na próxima seção.

A ideia básica dos trabalhos de Vieira-Pinto (2015) e Vieira-Pinto e Coelho (2016) foi investigar as estratégias de retomada anafórica do objeto direto de $3^{\text {a }}$ pessoa em amostras de fala espontâneas, seguindo de perto pressupostos já consagrados da Teoria da Variação e Mudança (cf. WEINREICH; LABOV; HERZOG, 2006 [1968], LABOV, 2008[1972]). O objetivo central das autoras foi identificar os condicionadores internos e externos que estariam favorecendo a retomada anafórica por uma categoria vazia (o conhecido objeto nulo, $\mathrm{ON}^{1}$ ) ou por um elemento pronunciado (um sintagma nominal ou um pronome, pleno ou clítico). Além disso, as autoras pretenderam verificar se haveria mudança, em tempo real e tempo aparente, no uso de determinadas estratégias, em especial o objeto nulo. Os exemplos de (1) a (4) ilustram as estratégias de retomada anafórica investigadas: ${ }^{2}$.

\footnotetext{
${ }^{1}$ A literatura sobre o objeto nulo em português é vasta. Cyrino $(1993,1994)$ são, ainda hoje, provavelmente os textos mais influentes (mas não os primeiros) sobre o assunto.

${ }^{2}$ Os códigos possuem os seguintes significados: MASC para masculino, FEM para feminino, JOV para menos de 50 anos de idade, VEL para mais de 50 anos de idade, FUND para até 8 anos de escolaridade, SUP para mais de 12 anos de escolaridade, 9 para década de 1990 e 2 para década de 2010.
} 


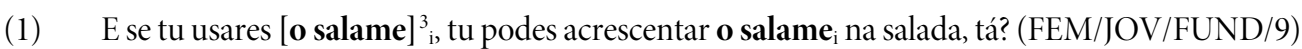

(2) Aí, [a minha mãe $]_{i}$, ela sofria da tireoide. Aí, ela foi, voltou pro Hospital de Caridade e operaram. Então, nessa época, era o Doutor (inint) que operou ela $\mathbf{a}_{\mathrm{i}}$. (FEM/VEL/FUND/9)

(3) [A Taís $]_{\mathrm{i}}$, eu ajudei muito. Porque ela foi pra creche pequenininha, pro berçário e os pais vieram chorando. Eu tava me aposentando, "ah, mas eu tenho tempo, deixa ela ficar comigo uns tempinho, até ela ficar maiorzinha", danada! Ajudei alfabetizá-la $\mathbf{a}_{\mathrm{i}}$, porque ela ia pro colégio Imaculada Conceição ou Coração de Jesus e ela tinha que saber muita coisa que no jardim não aprendia. (FEM/VEL/SUP/2)

(4) Como que eu vou cuidar de gêmeos, sua louca? E [dois menino] $]_{i}$, eu já tenho dois menino. Eu queria muito uma menina. Ah, dá $\emptyset_{\mathrm{i}}$ pra outra. Ah, vai ter alguém que vai querer $\emptyset_{\mathrm{i}}$ e vai dar bastante amor pra essas criança. (FEM/JOV/FUND/2)

Em ambos os trabalhos, as autoras consideraram algumas variáveis linguísticas (como os traços de animacidade e especificidade do antecedente anafórico) e extralinguísticas (como sexo, escolaridade e faixa etária dos informantes), conforme pode ser verificado na próxima seção. Contudo, há um debate relativamente recente na literatura sobre o objeto nulo em português brasileiro (PB) que foi desconsiderado nesses trabalhos. Creus e Menuzzi (2004) propuseram que o traço relevante para o condicionamento da retomada anafórica do objeto direto de $3^{\text {a }}$ pessoa fosse o gênero semântico do SN antecedente. O gênero semântico

\begin{abstract}
diz respeito à classificação que distingue substantivos que denotam seres sexuados de substantivos que denotam seres não sexuados; ou, talvez de forma mais precisa, o traço distingue substantivos que denotam sexo natural aparente, como homem, mulher, professor, cachorro, etc., de substantivos que não denotam sexo natural aparente, como mesa, livro, vítima, cônjuge, boneco, tartaruga, etc. Referentes inanimados são marcados negativamente para esse traço; substantivos animados, contudo, não possuem necessariamente um gênero semântico específico: pessoa, habitante, estudante, etc. Ou seja, alguns substantivos possuem gênero gramatical, mas não gênero semântico inerente. (OTHERO; SCHWANKE, 2017, p. 6)
\end{abstract}

De acordo com a hipótese original de Creus e Menuzzi (2004), um antecedente não especificado para gênero semântico deve favorecer a retomada anafórica com o objeto nulo, ao passo que um SN antecedente com gênero semântico aparente deve favorecer a retomada por pronome pleno. A ideia por trás dessa hipótese está relacionada ao sistema de anáfora em PB:

[...] a escolha entre ONs e PrPls [pronomes plenos] resultaria, basicamente, de um processo de concordância entre antecedente e forma anafórica: antecedentes com gênero semântico favorecem o uso de PrPls porque estas são as formas anafóricas especificadas para gênero; e antecedentes sem gênero semântico favorecem o uso de ONs precisamente porque ONs não possuem especificação para gênero semântico. (CREUS; MENUZZI, 2004, p. 161)

Essa ideia foi perseguida com algum sucesso em trabalhos recentes, como Pivetta (2015), Ayres (2016), Ayres e Othero (2016), Othero et al. (2016) e Othero e Schwanke (2017), por exemplo. Agora, neste artigo, revisamos a análise das entrevistas sociolinguísticas já apresentada em Vieira-Pinto (2015) e Vieira-Pinto e Coelho (2016), levando em conta justamente a variável "gênero semântico" do antecedente, como descrevemos em detalhe nas duas próximas seções. Nosso objetivo central aqui é verificar se o traço de gênero semântico do referente está, de fato, condicionando a retomada anafórica de objeto entre pronomes plenos e objetos nulos. Para isso, investigamos todos os SNs antecedentes com relação a esse traço, mas também anotamos os traços de animacidade e especificidade do SN antecedente, para fins de contraste com a hipótese do gênero semântico.

${ }^{3} \mathrm{O}$ recurso dos colchetes no SN, utilizado nos exemplos, indica qual é o referente do objeto direto anafórico. 
Com a queda do clítico pronominal de $3^{\text {a }}$ pessoa em $\mathrm{PB},-o$, $-a$ (a literatura sobre o assunto é vasta; ver, por exemplo, MONTEIRO, 1994, CYRINO, 1993, NUNES 1993, BAGNO, 2011, OTHERO; CARDOZO, 2017), as duas estratégias de retomada anafórica do objeto - por pronome pleno e por objeto nulo - se tornaram mais produtivas em PB (como mostraremos na próxima seção). Pretendemos, aqui, demonstrar qual é o condicionador de cada uma das duas estratégias, comparando, como mencionamos, os traços de animacidade, especificidade e gênero semântico do SN antecedente, tão caros à pesquisa sobre ON em PB (cf. MILESKI, 2014, para uma revisão de literatura relativamente recente). Por hipótese, imaginamos que a variável gênero semântico deva ser a mais relevante condicionadora da distribuição entre pronomes plenos e objetos nulos no corpus de fala que analisamos, seguindo resultados da literatura recente sobre 0 assunto ${ }^{4}$.

O texto está organizado como segue: na próxima seção, apresentamos detalhes do corpus que utilizamos e de alguns resultados de Vieira-Pinto (2015) sobre as formas de realização do objeto direto anafórico; na seção 3, apresentamos a nossa discussão dos dados e os resultados a que chegamos. Finalmente, encerramos o artigo com algumas palavras de fechamento, nas Considerações Finais.

\section{PONTO DE PARTIDA}

Os dados empíricos desta reanálise foram extraídos de duas amostras analisadas por Vieira-Pinto (2015) e por Vieira-Pinto e Coelho (2016), compreendendo 16 entrevistas sociolinguísticas realizadas em zonas mais urbanas de Florianópolis, estratificadas segundo as variáveis sexo (masculino e feminino), faixa etária (menos de 50 anos e mais de 50 anos) e escolaridade (até 8 anos de escolaridade e mais de 12 anos de escolaridade), assim organizadas:

(i) Amostra 1990 - oito entrevistas do Banco Base do Núcleo VARSUL;

(ii) Amostra 2010 - oito entrevistas da Amostra Floripa, que também pertence ao Núcleo VARSUL (agência de Santa Catarina).

Dessas amostras, foram coletadas todas as sentenças com verbo transitivo direto (biargumental) ou verbo bitransitivo (triargumental) que têm como argumento interno um objeto direto anafórico de terceira pessoa, cujo antecedente seja um sintagma nominal.

No trabalho de 2016, Vieira-Pinto e Coelho investigaram 666 ocorrências de objetos diretos anafóricos de sintagma nominal, sendo 302 dados de objeto nulo (45\%) e 364 dados de objetos expressos (55\%), como o Gráfico 1 mostra.

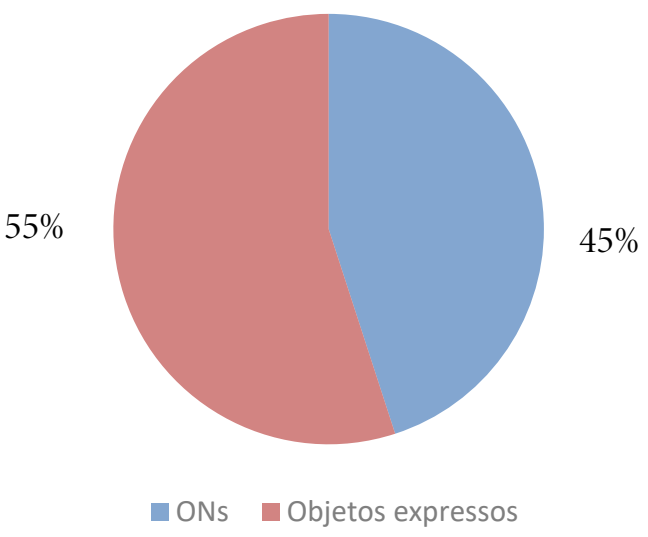

Gráfico 1: Ocorrências de retomadas anafóricas de $3^{\text {a }}$ pessoa em função de objeto direto, em amostras de fala de Florianópolis.

Fonte: Adaptado de Vieira-Pinto e Coelho (2016, p. 251)

\footnotetext{
${ }^{4} \mathrm{O}$ ineditismo de nosso trabalho se deve à análise de língua falada atual (décadas de 1990 e 2010). Não há nenhum outro trabalho que tenha investigado o condicionamento da retomada anafórica do objeto direto em PB com a variável "gênero semântico" do SN antecedente em amostras de fala contemporâneas em PB.
} 
A análise levou em conta três formas de realização do objeto expresso, assim distribuídas nas duas amostras: 343 ocorrências de sintagmas nominais anafóricos, 20 ocorrências de pronomes plenos e uma ocorrência de pronome clítico ${ }^{5}$ e a retomada anafórica por objeto nulo, como ilustram os exemplos de (1) a (4), apresentados na seção anterior. Essas estratégias estão detalhadas nos índices apresentados na Tabela 1 .

\begin{tabular}{c|c} 
Tipo de retomada & Número de ocorrências \\
\hline SNs & $343(51,5 \%)$ \\
\hline Pronomes plenos & $20(3,4 \%)$ \\
\hline Pronomes clíticos & $1(0,1 \%)$ \\
\hline Objetos nulos & $302(45 \%)$ \\
\hline Total & $\mathbf{6 6 6}(\mathbf{1 0 0} \%)$
\end{tabular}

Tabela 1: Ocorrências de retomadas anafóricas expressas em função de objeto direto, em amostras de fala de Florianópolis. Fonte: Adaptada de Vieira-Pinto (2015, p. 115).

Considerando as duas amostras separadamente, as autoras observaram que (i) os objetos nulos apresentaram um leve crescimento de uma década a outra (de 42,9\% a 48,5\%); e (ii) os objetos expressos apresentaram uma pequena queda nessa mesma época (de $57,1 \%$ para 51,5\%), atestando que a estratégia de retomada por ON é uma marca gramatical cada vez mais presente em PB (cf. TARALLO, 1983; DUARTE, 1989; CYRINO, 1993, 1994).

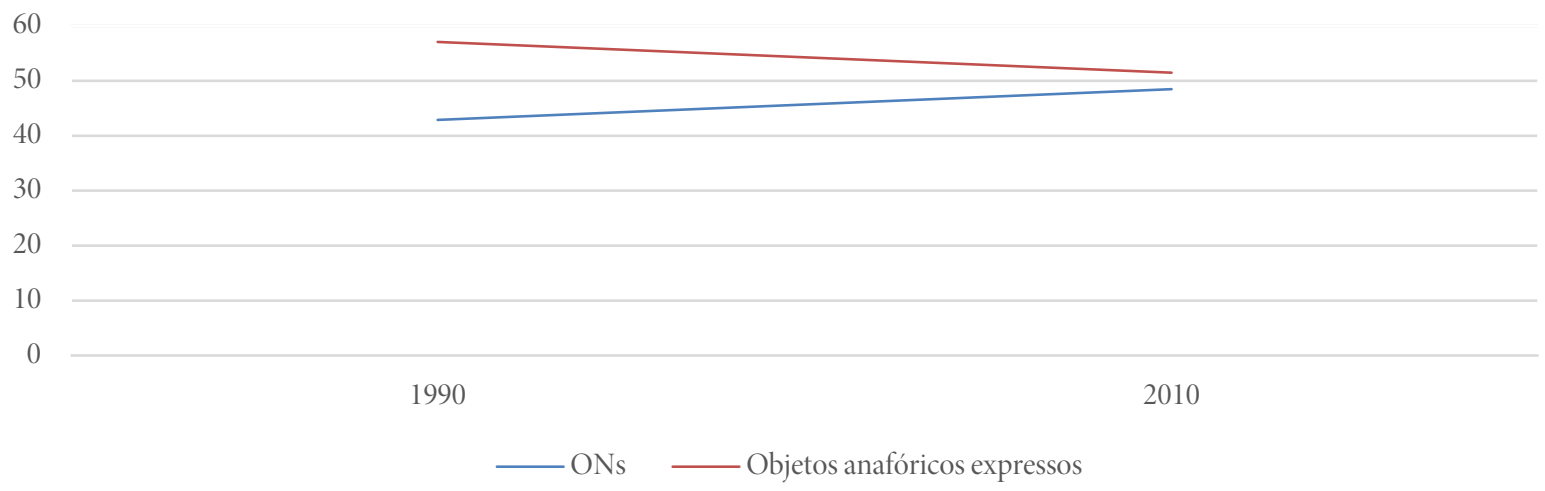

Gráfico 2: Ocorrências de retomadas expressas e de retomadas nulas em duas sincronias, em amostras de fala de Florianópolis. Fonte: Vieira-Pinto e Coelho (2016, p. 252)

Os índices de ONs de uma década a outra mostram, para além de um indicativo de mudança em curso, que essa estratégia é produtiva na fala de Florianópolis. Para observar quais as variáveis semânticas que condicionam esse uso resolvemos agrupar os dados das duas amostras neste estudo de reanálise, opondo essa estratégia aos pronomes anafóricos plenos. Partimos, portanto, dos 302 dados de objeto nulo e dos 20 dados de pronomes plenos de terceira pessoa encontrados na fala de Florianópolis. As variantes controladas são ilustradas nos exemplos a seguir.

(5) Eu usei muito de [futebol de salão] $]_{i}$ pratiquei $\emptyset_{\mathrm{i}}$ muito, mas depois dei uma parada [...] Então, eu hoje jogo $\emptyset_{\mathrm{i}}$ somente às quartas-feiras. (MASC/JOV/FUND/9)

\footnotetext{
${ }^{5}$ Encontrar apenas uma única ocorrência de pronome clítico de $3^{\text {a }}$ pessoa nos dados reforça o fato de que os clíticos pronominais de $3^{\text {a }}$ pessoa verdadeiramente já não fazem parte da fala vernacular em PB (cf., nesse sentido, MONTEIRO, 1994; NUNES, 1996; OLIVEIRA, 2007; BAGNO, 2011, OTHERO; CARDOZO, 2017).
} 
(6) Mas [esse ajudante $]_{i}$ era completamente louco, era completa-, ele tinha sido internado e tudo, já. [...] Até hoje, de vez em quando eu encontro ele $e_{\text {. }}$ (FEM/JOV/FUND/9)

O principal objetivo desta reanálise é testar a significância de três variáveis semânticas, a saber: (i) o traço de animacidade do SN antecedente; (ii) o traço de especificidade do SN antecedente; e (iii) o traço de gênero semântico do SN antecedente. As duas primeiras variáveis já foram investigadas por Vieira-Pinto (2015) e Vieira-Pinto e Coelho (2016) ${ }^{6}$. Os resultados das autoras indicaram que a animacidade do constituinte retomado é uma grande condicionadora do objeto nulo, enquanto a especificidade, apesar de mostrar índices percentuais reveladores, não foi selecionada pelo pacote estatístico utilizado. A terceira variável entra na análise justamente para observar se a hipótese de Creus e Menuzzi (2004), retomada por Pivetta (2015) e Othero et al. (2016), sobre a correlação entre [+gênero semântico] e objeto expresso por pronome pleno e entre [-gênero semântico] e retomada por objeto nulo, pode ser atestada na fala florianopolitana. Interessa observar se a variável gênero semântico se constitui como a força motivadora mais importante da estratégia do objeto nulo. Para essa análise utilizamos o pacote estatístico Goldvarb X.

\section{DESCRIÇÃO DOS RESULTADOS}

Para o estudo de reanálise das 322 ocorrências de objeto direto anafórico de terceira pessoa encontradas na fala de Florianópolis (302 casos de objetos nulos $(93,8 \%)$ e $20 \operatorname{casos}^{7}$ de pronomes plenos $(6,2 \%)$ ), investigamos a força das três variáveis semânticas sobre a estratégia do objeto nulo. O programa estatístico selecionou as duas variáveis: 'gênero semântico do SN antecedente' e 'animacidade do SN antecedente' como condicionadoras da estratégia de ON. Seguindo a mesma tendência que identificamos em Vieira-Pinto (2015) e Vieira-Pinto e Coelho (2016), a variável 'especificidade do SN antecedente' não foi selecionada. Os resultados das tabelas seguintes apresentam os percentuais e os pesos relativos encontrados em cada uma das variáveis selecionadas, além de alguns cruzamentos. Comecemos com os índices da variável 'gênero semântico do SN antecedente', sobre o ON.

\begin{tabular}{c|c|c|c} 
Gênero semântico do SN antecedente & Apl/Total & $\%$ & Peso Relativo \\
\hline [-gênero semântico] & $264 / 267$ & $98,9 \%$ & 0,58 \\
\hline [+gênero semântico] & $38 / 55$ & $69,1 \%$ & 0,15 \\
\hline Total & $302 / 322$ & $93,8 \%$ &
\end{tabular}

Log likelihood $=-45.334$. Significance $=0.031$.

Tabela 2: Frequência de objeto nulo, segundo a variável 'gênero semântico do SN antecedente', em amostras de fala de Florianópolis. Fonte: os autores

Os resultados apontam que antecedentes com traço [-gênero semântico] condicionam o uso do objeto nulo em 0,58 de peso relativo, conforme o exemplo em (7) indica, enquanto antecedentes com traço [+gênero semântico] inibem o uso de objeto nulo (0,15), tal como previsto por Creus e Menuzzi (2004) e Othero et al. (2016).

\footnotetext{
${ }^{6}$ Nos trabalhos de Vieira-Pinto (2015) e Vieira-Pinto e Coelho (2016), a variável 'animacidade do referente’ foi selecionada pelo pacote estatístico Goldvarb X apenas para a amostra de 1990. Entretanto, a variável 'especificidade do referente' não foi selecionada em nenhuma amostra. Outras variáveis linguísticas que foram selecionadas, mas não serão investigadas neste trabalho de reanálise, foram as seguintes: 'função sintática do referente' (nas duas amostras) e 'transitividade verbal e estrutura projetada pelo verbo' (na amostra de 2010).

${ }^{7}$ Acreditamos que o baixo número de ocorrências da variante 'pronome pleno' (20 casos num total de 322 ocorrências de objeto anafórico de terceira pessoa) devese ao fato de os dados de fala serem provenientes de entrevistas sociolinguísticas. Segundo Labov (2008 [1972]), mesmo estando à vontade no momento da entrevista, o falante nem sempre utiliza a fala vernacular em todas as situações de entrevista. Quando faz avaliação sobre a língua, ou avaliação crítica sobre assuntos polêmicos, por exemplo, o falante presta mais atenção à sua fala, evitando formas que são menos prestigiadas na sociedade. O objeto nulo, nesses casos, seria a forma preferida.
} 
(7) Era um fusca.

$[\text { Fusca }]_{i}$ !

Na verdade, eu comprei $\emptyset_{\mathrm{i}}$ zero, ele me deu $\emptyset_{\mathrm{i}}$ zero me deu zero, carro zero.(MAS/VEL/SUP/2)

Os três únicos dados encontrados em nossa amostra de objeto direto anafórico expresso com pronome pleno em que o antecedente apresenta traço [-gênero semântico] foram os seguintes:

(8) Você tinha [moto de trilha $]_{i}$, então?

Tinha. Quando eu fiz... eu sempre tive. Desde pequeno assim, quando eu tinha doze, treze anos eu já tinha. Daí, quando eu fiz dezoito, a gente precisa tirar a carteira [...] Aí, vendi ela (MASC/JOV/FUND/2)

(9) Também não tenho mais energia pra ir pra sala de aula. Tá muito mudado, neh, [essa criançada $]_{i}$. Tudo tem suas épocas, neh? Agora passou, passou. Nós estávamos conversando sobre isso antes, neh?

É, é a tal coisa. A gente gosta muito, tal, agrada, trata eles $_{\mathrm{i}}$ bem na biblioteca. Mas não é assim, como tem a questão de sentar dentro da sala de aula. Neh?(FEM/VEL/SUP/9)

(10) Porque eu, na época, trabalhava na receita federal. E a gente tinha, eu, no caso, fazia parte da associação do ministério da fazenda, que era lá na Lagoa, não sei se vocês conhece, chama-se ACEFAS. Então eu reuni [meus colegas] $]_{i}$ aqui e levava eles ${ }_{i}$ pra lá pra gente bate uma bola. (MASC/VEL/FUND/2)

Dois desses três casos são de um pronome retomando um SN que expressa uma ideia de "coletivo": [essa criançada] e [meus colegas]. Curiosamente, Othero e Schwanke (2017, p. 18), em seu estudo sobre a retomada anafórica do objeto em um corpus escrito de PB, já tinham reparado que a concordância ideológica (como a do exemplo (9)) e a retomada de SNs "coletivos" (como a do exemplo (10)) parecem favorecer o uso de pronomes:

Encontramos três casos de retomada anafórica com concordância ideológica, todos com referentes [-gs] e retomados por pronomes, o que nos leva a crer que, nos casos desse tipo de concordância, a tendência é que o pronome seja mantido.

[...] [Sobre SNs coletivos:] Em nossos dados, 6 casos de referentes [-gs] retomados por pronomes se encaixam nessa categoria, i.e. todos os antecedentes, nesse caso, fazem denotação a um grupo de pessoas ou coletivos de indivíduos específicos. [...] todos os casos que encontramos ( 6 casos) desse tipo foram retomados por pronome (e não $\mathrm{ON}$, como esperávamos). Em todos esses casos, trata-se de concordância gramatical, o que pode comprovar - caso seja feita uma análise mais aprofundada - a hipótese de que, em casos de referentes [+animados], a influência maior é do gênero gramatical, e não semântico.

Por outro lado, os antecedentes com traço [+gênero semântico] se mostram fortes condicionantes do objeto expresso com o pronome pleno, como vemos no seguinte exemplo:

(11) Eles moram na Alemanha, neh? Porque ela casou com [um alemão $]_{i}$. Então, ela vai- vai nascer na Alemanha e vem se batizar aqui. Ela conheceu ele $_{i}$ numa excursão que ela era- era estudante.(FEM/VEL/FUND/9)

Considerando os resultados estatísticos da variável 'animacidade do antecedente' sobre o objeto nulo, os índices mostram que antecedentes [-animado] condicionam o uso de objeto nulo em 0,69 de peso relativo, enquanto os antecedentes [+animado] condicionam o uso de pronome pleno, com apenas 0,08 de nulo, conforme os índices da tabela e os exemplos abaixo indicam. 


\begin{tabular}{c|c|c|c} 
Animacidade do SN antecedente & Apl/Total & $\%$ & Peso Relativo \\
\hline$[$-animado $]$ & $236 / 237$ & $99,6 \%$ & 0,69 \\
\hline$[$ +animado] & $66 / 85$ & $77,4 \%$ & 0,08 \\
\hline Total & $302 / 322$ & $93,8 \%$ &
\end{tabular}

Log likelihood $=-45.334$. Significance $=0.031$.

Tabela 3: Frequência de objeto nulo, segundo a variável 'animacidade do SN antecedente', em amostras de fala de Florianópolis.

Fonte: os autores.

(12) [Trinta e um créditos $]_{i}$ era o limite que eu podia fazer. Estava fazendo $\emptyset_{\mathrm{i}}$ e trabalhando no banco. (FEM/JOV/SUP/9)

(13) [Meu esposo $]_{i}$ é da ilha. [...] Conheci ele ${ }_{i}$, porque tinha uma amiga que tinha um namorado e o namorado era amigo dele e trouxe pra ele vim pros Coqueiros. (FEM/VEL/SUP/2)

A fim de visualizar melhor a relação entre as variáveis linguísticas semânticas, fizemos alguns cruzamentos entre o 'gênero semântico do antecedente' e as variáveis 'animacidade do antecedente' e 'especificidade do antecedente', conforme indicam os índices percentuais apresentados nas tabelas 4 e 5 que seguem.

\begin{tabular}{c|c|c|c|c} 
Gênero semântico do SN antecedente & \multicolumn{2}{|c|}{ [+gênero semântico] } & \multicolumn{2}{c}{ [-gênero semântico] } \\
\hline Animacidade do SN antecedente & Apl/Total & $\%$ & Apl/Total & $\%$ \\
\hline$[+$ animado] & $38 / 55$ & $69 \%$ & $28 / 30$ & $93 \%$ \\
\hline$[$-animado] & $0 / 0^{8}$ & -- & $236 / 237$ & $99 \%$
\end{tabular}

Tabela 4: Frequência de objeto nulo, no cruzamento entre as variáveis 'gênero semântico do SN antecedente' e ‘animacidade do SN antecedente', em amostras de fala de Florianópolis.

Fonte: os autores.

Com esse cruzamento, podemos notar que, independentemente do traço de animacidade do antecedente, os antecedentes com traço [-gênero semântico] são contextos condicionadores do objeto nulo e inibidores de pronomes plenos. Dos 30 dados com antecedente [-gênero semântico] e traço [+ animado], 28 são de objetos nulos (93\%) e apenas dois casos de pronomes plenos (7\%). Dos 237 dados com antecedente [-gênero semântico] e traço [- animado], 236 são de nulos (99\%) e apenas um caso de pronome pleno (1\%). Ambos os índices revelam percentuais acima de $90 \%$ de objetos nulos e abaixo de $10 \%$ de pronomes plenos. Os exemplos (14) e (15) ilustram, a seguir, esses contextos favorecedores.

(14) Sabe como é que são esses funcionários, né, gente? Essa, essa qualidade, são [pessoas que não estudaram muito] ${ }_{\mathrm{i}}$, então tem que ensinar $\emptyset_{\mathrm{i}}$ a falar, ensinar $\emptyset_{\mathrm{i}}$ a atender às pessoas, ensinar $\emptyset_{\mathrm{i}}$ a ser educado, tudo isso ele faz. (FEM/VEL/SUP/2)

(15) Hãm, e sobre, sobre a cultura geral da da ilha. É... como o senhor se sente em relação [às festas típicas do bairro] ${ }_{\mathrm{i}}$, sobre....

\footnotetext{
${ }^{8}$ Não encontramos dados com antecedente [-animado] e [+gênero semântico] nas amostras investigadas. Tal caso só poderia estar relacionado a um objeto inanimado que pudesse ter o gênero marcado, algo como um boneco ou boneca - é o que Ayres (2016) reporta ter encontrado, por exemplo.
} 
Eu vou ser sincero, eu já... antigamente, eu até nem dava bola e nem achava $\emptyset_{\mathrm{i}}$ nem bonito, só que a gente participava. (MAS/VEL/SUP/2)

Dos 55 dados com antecedente [+gênero semântico] e traço [+animado], 38 são casos de objetos nulos (69\%) e 17 de pronomes plenos (31\%). Se o traço [+animado] do antecedente estivesse atuando no favorecimento do pronome pleno, esperaríamos que ambos os índices de antecedentes [+animados] fossem muito próximos, independentemente do traço semântico de gênero. Entretanto, o que vemos nos resultados da tabela é uma diferença bem acentuada entre os índices de antecedente [+animado] e [+gênero semântico], com 69\% de nulos e 31\% de pronomes plenos, e os índices de antecedente [+animado] e [-gênero semântico], com 93\% de nulos e apenas 7\% de plenos. Os resultados desse cruzamento revelam, portanto, o favorecimento da variável 'gênero semântico do SN antecedente' sobre a variável 'animacidade do SN antecedente' na realização do objeto nulo pelos informantes florianopolitanos.

Ao observarmos o cruzamento entre as variáveis 'gênero semântico do SN antecedente' e 'especificidade do SN antecedente', novamente o gênero semântico se destaca. Vejamos os resultados da Tabela 5.

\begin{tabular}{c|c|c|c|c} 
Gênero semântico do SN antecedente & \multicolumn{2}{|c|}{ [+gênero semântico] } & \multicolumn{2}{|c}{ [-gênero semântico] } \\
\hline Especificidade do SN antecedente & Apl/Total & $\%$ & Apl/Total & $\%$ \\
\hline$[+$ específico] & $37 / 52$ & $71 \%$ & $83 / 85$ & $98 \%$ \\
\hline$[$-específico] & $1 / 3$ & $33 \%$ & $181 / 182$ & $99 \%$
\end{tabular}

Tabela 5: Frequência de objeto nulo, no cruzamento entre as variáveis 'gênero semântico do SN antecedente' e 'especificidade do SN antecedente', em amostras de fala de Florianópolis.

Fonte: os autores.

Como esperávamos, independentemente da especificidade do antecedente, os antecedentes com traços [-gênero semântico] influenciam o uso da variante objeto nulo, com índices quase categóricos: dos 85 dados com antecedente [+específico], 83 são casos de objetos nulos (98\%), e, dos 182 dados com antecedente [-específico], 181 são casos de nulos (99\%). Esses índices estão ilustrados nos exemplos a seguir.

(16) Ah, tinha $[\mathbf{a} \text { brincadeira das chacretes }]_{\mathrm{i}}$, a gente dançava, o meu pai adorava $\emptyset_{\mathrm{i}}$, achava $\emptyset_{\mathrm{i}}$ lindo! (FEM/JOV/FUND/9)

(17) Adorei ser professora. Muito mal remunerada, na época muito valorizada, os pais davam toda atenção e depositavam toda confiança no professor, sabe? Olha "a senhora que sabe, a senhora que manda" e a gente, quando tinha [algum problema $]_{i}$, ia na família ajudar a resolver $\emptyset_{\mathrm{i}}$ e era muito tranquilo. (FEM/VEL/SUP/2)

Quando o antecedente apresenta os traços de [+gênero semântico] os percentuais de nulos são mais baixos do que os encontrados para antecedente [-gênero semântico], independentemente da especificidade do antecedente. Dos 52 casos de antecedente [+específico], 37 são de estratégias de objetos nulos (71\%) e 15 de pronomes plenos (29\%). Dos três casos de antecedente [específico], um caso é de objeto nulo (33\%) e dois de pronomes plenos (67\%). A diferença, entretanto, entre os fatores [+específico] e [-específico] com antecedente [+gênero semântico] não pode ser levada em conta, pois encontramos nas amostras investigadas apenas três dados com antecedente [-específico]. Os exemplos a seguir ilustram esses casos de [+gênero semântico] combinados com traços [+específico], em (18), e com traços [-específico], em (19).

(18) Gosta de ir ao cinema?

[A minha mulher $]_{i}$ gosta muito, mas eu acompanho $\emptyset_{\mathrm{i} \cdot}$ (MAS/VEL/SUP/9) 
(19) Pra você ver, eu, no meu, no meu, meu tempo, que eu era jovem, se eu embarcado no ônibus, no ônibus (inint.). Então vinha [uma moça $]_{i}$, (inint) moça casada, neh? então cedia o lugar pra ela (inint.) porque o regulamento marca. Nesses ônibus ainda aí, nesses ônibus aí, eu vejo, neh? ele de cabelo branco e aquele jovem sentado aí na "areia”. Eu chamo $\emptyset_{\mathrm{i}}$ e dou lugar pra ela sentar. (MASC/VEL/FUND/9)

Além do mais, essa distinção entre antecedente [+específico] e [-específico] não é relevante se comparada aos antecedentes com traço [-gênero semântico], contextos quase categóricos para o objeto nulo (98\% e 99\%), independentemente da especificidade do antecedente, conforme já salientamos.

Esses resultados corroboram as previsões de Creus e Menuzzi (2004) e as análises de Othero et. al (2016) em relação à força da variável 'gênero semântico do antecedente' nas formas de objeto direto anafórico. O traço [+gênero semântico] do antecedente favorece o objeto expresso por pronome pleno, ao passo que antecedentes sem gênero semântico aparente favorecem a retomada por objeto nulo. Tudo indica que apenas um único traço semântico do antecedente - o gênero semântico - seja capaz de explicar as estratégias de retomada anafórica do objeto nas amostras de fala aqui investigadas, no que se refere aos objetos nulos e aos pronomes plenos.

\section{CONSIDERAÇÕES FINAIS}

Após reanalisar todas as 322 ocorrências de retomadas anafóricas com pronomes plenos (20 ocorrências) e objetos nulos (302 ocorrências) em nossa amostra, levando em consideração os três traços do SN antecedente (animacidade, especificidade e gênero semântico), concluímos que o traço de gênero semântico atua como fator condicionador para o fenômeno: os SNs antecedentes que têm gênero semântico identificado favorecem a retomada anafórica com o pronome pleno; os SNs antecedentes que não têm gênero semântico identificado favorecem a retomada com o objeto nulo. Demos mais um passo na comprovação dessa hipótese (originalmente proposta em CREUS; MENUZZI, 2004) que tenta explicar a retomada anafórica de objeto em PB.

O traço de gênero semântico, na verdade, parece atuar não somente sobre o fenômeno da retomada de objeto direto anafórico de $3^{\mathrm{a}}$ pessoa, mas sobre o fenômeno de retomada anafórica de objeto direto em geral em PB (envolvendo pronomes e ONs, de $1^{\mathrm{a}}$, $2^{\mathrm{a}}$ e $3^{\mathrm{a}}$ pessoas gramaticais), como sugerem os trabalhos de Schwenter (2006) ${ }^{9}$ e Othero et al. (2016) e como tenta mostrar o trabalho de Othero e Spinelli (2017). Se esse for realmente o caso, podemos esperar que esse traço (gênero semântico) esteja por trás, na verdade, da distribuição entre pronomes versus elementos vazios não apenas na retomada anafórica de objeto direto, mas também na função de sujeito. Isso nos permitiria chegar a uma generalização interessante: a de que os referentes marcados com gênero semântico favoreceriam o uso de pronomes retos em PB, seja na função de objeto direto, seja na função de sujeito. Isso aconteceria porque o sujeito expresso pronominal e o sujeito nulo parecem estar relacionados às mesmas propriedades dos referentes consideradas, normalmente, como relevantes para o fenômeno do objeto nulo - cf. a hierarquia referencial proposta por Cyrino, Kato e Duarte (2000) (além dos trabalhos de KATO, 1999 e KATO; DUARTE, 2014, por exemplo). Além disso, sabemos, pelo menos desde o trabalho de Tarallo (1983), que há uma relação entre os fenômenos do sujeito nulo e do objeto nulo em PB (estudos diacrônicos mostram que a mudança no sistema pronominal do PB ocasionou a queda do sujeito nulo e o aumento do objeto nulo, cf. OLIVEIRA, 1989; TARALLO, 1983; DUARTE, 1989, 1993, 1995, 2003; BAGNO, 2011; entre outros). Fica aqui nossa sugestão de pesquisa: analisar as ocorrências de sujeito nulo e pronominal com base no gênero semântico dos SNs antecedentes.

\footnotetext{
${ }^{9}$ Schwenter (2006) desconhecia a hipótese do gênero semântico; por isso, não leva em consideração o traço de gênero semântico em seu trabalho. Contudo, ele percebe um "estranhamento" quando tenta sistematizar a retomada anafórica do objeto em PB e declara (p. 26): "o PB é uma variedade que apresenta um sistema 'dividido' de marcação de objetos diretos anafóricos. Todos os objetos anafóricos animados (principalmente os +humanos) e específicos são preferencialmente codificados de maneira explícita, enquanto todos os outros são preferencialmente codificados como objetos nulos”. Othero et al. (2016), levando em conta o traço de gênero semântico, terminam, justamente, com essa "divisão" no sistema de marcação de objetos diretos anafóricos em PB percebida por Schwenter (2006).
} 


\section{REFERÊNCIAS}

AYRES, M. R. Aspectos condicionadores do objeto nulo e do pronome pleno em português brasileiro: uma análise da fala infantil. 2016. 63 f. Dissertação (Mestrado) - Pontifícia Universidade Católica do Rio Grande do Sul, Porto Alegre, 2016.

AYRES, M. R.; OTHERO, G. A. Aspectos condicionadores do objeto nulo e do pronome pleno em português brasileiro: uma análise da fala infantil. Caderno de Squibs: Temas em estudos formais da linguagem, Brasília, v. 2, n. 2, p. 1-12, 2016.

BAGNO, M. Gramática pedagógica do português brasileira. São Paulo: Parábola Editorial, 2011.

CREUS, S.; MENUZZI, S. M. Sobre o papel do gênero semântico na alternância entre objetos nulos e pronomes plenos em português brasileiro. Revista da ABRALIN, Florianópolis, v. 3, n. 1-2, p. 149-176, 2004.

CYRINO, S. M. Observações sobre a mudança diacrônica no português do Brasil: objeto nulo e clíticos. In: ROBERTS, I.; KATO, M. A. (Org.). Português brasileiro: uma viagem diacrônica. Campinas: Ed. da Unicamp, 1993. p. 163-184.

CYRINO, S. M. O objeto nulo no português do Brasil: um estudo sintático-diacrônico. 1994. 216 f. Tese de doutorado, UNICAMP, Campinas, 1994.

CYRINO, S. M. L.; DUARTE, M. E.; KATO, M. A. Visible subjects and invisible clitics in Brazilian Portuguese. In: KATO, M. A.; NEGRÃO, E. V. (Ed.) Brazilian portuguese and the null subject parameter. Frankfurt: Vervuert-Iberoamericana. p. 55-104, 2000.

DUARTE, M. E. Clítico acusativo, pronome lexical e categoria vazia no português do Brasil. In: TARALLO, F. (Org.) Fotografias sociolingüísticas. Campinas: Editora da Unicamp, 1989. p. 19-34.

DUARTE, M. E. Do pronome nulo ao pronome pleno: a trajetória do sujeito no português do Brasil. In: ROBERTS, I.; KATO, M. A. (Org.). Português brasileiro: uma viagem diacrônica. Campinas: Ed. da Unicamp, 1993. p. 107-128.

DUARTE, M. E. A perda do princípio "evite pronome" no português brasileiro. 1995. 151 f. Tese (Doutorado) - Instituto de Estudos da Linguagem, Universidade de Campinas, Campinas, 1995.

DUARTE, M. E. A evolução na representação do sujeito pronominal em dois tempos. In: PAIVA, M. C.; DUARTE, M. E. (Org.) Mudança linguística em tempo real. Rio de Janeiro: Contra Capa, 2003. 115-128.

KATO, M. A. Strong pronouns and weak pronominals in the null subject parameter. Probus (Dordrecht), Berlin, v. 11, n. 1, p. 1-37, 1999.

KATO, M. A.; DUARTE, M. E. Restrições na distribuição de sujeitos nulos no Português Brasileiro. Revista Veredas, v. 18, n. 1, p. 122, 2014.

LABOV, W. Padrões sociolinguísticos. São Paulo: Parábola, 2008. [1972].

MILESKI, I. Uma discussão sobre condicionamentos semânticos do uso do objeto nulo no português brasileiro. Via Litterae, v. 6 , n. 2,2014

MONTEIRO, J. L. Pronomes pessoais. Fortaleza: EUFC, 1994.

NUNES, J. M. Direção de cliticização, objeto nulo e pronome tônico na posição de objeto em português brasileiro. In: ROBERTS, I.; KATO, M. A. (Org.). Português brasileiro: uma viagem diacrônica. Campinas: Unicamp, 1993. p. 207-222.

OLIVEIRA, D. P. O preenchimento, a supressão e a ordem do sujeito e do objeto em sentenças do português do Brasil: um estudo quantitativo. In: TARALLO, F. (Org.). Fotografias sociolinguísticas. Campinas: Pontes, 1989. p. 51-63. 
OLIVEIRA, S. M. Objeto direto nulo, pronome tônico de 3a pessoa, SN anafórico e clítico acusativo no português brasileiro: uma análise de textos escolares. ReVEL, v. 5, n. 9, p. 1-30, 2007.

OTHERO, G. A.; AYRES, M. R.; SCHWANKE, C.; SPINELLI, A. C. A relevância do traço gênero semântico na realização do objeto nulo em português brasileiro. Working Papers em Linguística, Florianópolis, v. 17, n.1, p. 64-85, 2016.

OTHERO, G. A.; CARDOZO, R. W. A ordem pronominal em português brasileiro: da ênclise à próclise, do clítico ao tônico (or There and Back Again, a Word Order's Holiday). Fórum Linguístico, v. 14, n. 1, p. 1717-1734, 2017.

OTHERO, G. A.; SCHWANKE, C. Retomadas anafóricas de objeto direto em português brasileiro escrito. Revista de Estudos da Linguagem, v.26, n.1, p. 147-185, 2017.

OTHERO, G. A.; SPINELLI, A. C. Analisando a retomada anafórica do objeto direto em português falado. Revista Letras, v. 96 , p. 174-195, 2017.

PIVETTA, V. Objeto direto anafórico no português brasileiro: uma discussão sobre a importância dos traços semântico-pragmáticos animacidade/especificidade vs. gênero semântico. 2015. 129 f. Dissertação (Mestrado) - Universidade Federal do Rio Grade do Sul, Porto Alegre, 2015.

SCHWENTER, S. A. Null objects across South America. Selected proceedings of the 8th Hispanic Linguistics Symposium. Somerville: Cascadilla Press, 2006.

SCHWENTER, S.; SILVA, G. Overt vs. null direct objects in spoken Brazilian Portuguese: a semantic/pragmatic account. Hispania, v.85, n.3, p. 577-586, 2002.

SCHWENTER, S.; SILVA, G. Anaphoric direct objects in spoken BrazilianPortuguese: Semantics and pragmatics. Revista Internacional de Linguística Iberoamericana, Berlin, v.1, n.2, p. 99-123, 2003.

TARALLO, F. Relativization Strategies in Brazilian Portuguese. Doctoral dissertation, Univ. of Pennsylvania, Philadelphia, 1983.

VIEIRA-PINTO, C. A. Variação do objeto anafórico acusativo na fala de Florianópolis. Dissertação de Mestrado, Universidade Federal de Santa Catarina, 2015.

VIEIRA-PINTO, C. A.; COELHO, I. L. O objeto direto anafórico de SN: uma análise da fala de Florianópolis em duas sincronias. ReVEL, Porto Alegre, Edição Especial. n. 13, p. 245-263, 2016.

WEINREICH, U; LABOV, W; HERZOG, M. Fundamentos empíricos para uma teoria da mudança linguística. São Paulo: Parábola, 2006. [1968]. 